\title{
Attenuation of Inflammatory Events in Human Intervertebral Disc Cells with a Tumor Necrosis Factor Antagonist
}

\author{
S. Michael Sinclair ${ }^{1}$, Mohammed F. Shamji ${ }^{2}$, Jun Chen ${ }^{1}$, Liufang Jing ${ }^{1}$, William J. \\ Richardson $^{3}$, Christopher R. Brown ${ }^{3}$, Robert D. Fitch ${ }^{3}$, and Lori A. Setton ${ }^{1,3}$ \\ ${ }^{1}$ Department of Biomedical Engineering, Duke University, Durham, NC, USA \\ ${ }^{2}$ Division of Neurosurgery, The Ottawa Hospital, Ottawa, ON, Canada \\ ${ }^{3}$ Department of Surgery, Division of Orthopaedic Surgery, Duke University, Durham, NC, USA
}

\section{Abstract}

Study Design-The inflammatory responses of primary human intervertebral disc (IVD) cells to tumor necrosis factor (TNFa) and an antagonist were evaluated in vitro.

Objective-To investigate an ability for soluble TNF receptor type II (sTNFRII) to antagonize tumor necrosis factor alpha (TNFa) induced inflammatory events in primary human IVD cells in vitro.

Summary of Background Data-TNFa is a known mediator of inflammation and pain associated with radiculopathy, and IVD degeneration. Soluble TNF receptors (sTNFR) and their analogues are of interest for the clinical treatment of these IVD pathologies although information on the effects of sTNFR on human IVD cells remains unknown.

Methods-IVD cells were isolated from surgical tissues procured from 15 patients and cultured with or without $1.4 \mathrm{nM} \mathrm{TNFa}(25 \mathrm{ng} / \mathrm{ml})$. Treatment groups were co-incubated with varying doses of sTNFRII (12.5-100nM). Nitric oxide (NO), prostaglandin $\mathrm{E}_{2}\left(\mathrm{PGE}_{2}\right)$, and interleukin-6 (IL6) levels in media were quantified to characterize the inflammatory phenotype of the IVD cells.

Results-Across all patients, TNFa induced large, statistically significant increases in NO, $\mathrm{PGE}_{2}$, and IL6 secretion from IVD cells compared to controls (60, 112, and 4-fold increases, respectively; $\mathrm{p}<0.0001)$. Coincubation of TNFa with nanomolar doses of sTNFRII significantly attenuated the secretion of $\mathrm{NO}$ and $\mathrm{PGE}_{2}$ in a dose-dependent manner, while IL6 levels were unchanged. Mean $\mathrm{IC}_{50}$ values for $\mathrm{NO}$ and $\mathrm{PGE}_{2}$ were found to be $35.1 \mathrm{nM}$ and $20.5 \mathrm{nM}$, respectively.

Conclusions-Nanomolar concentrations of sTNFRII were able to significantly attenuate the effects of TNFa on primary human IVD cells in vitro. These results suggest this soluble TNF receptor to be a potent TNF antagonist with potential to attenuate inflammation in IVD pathology.

\section{INTRODUCTION}

Tumor necrosis factor (TNF) is one of several pro-inflammatory cytokines believed to contribute to the painful symptoms and progressive pathology of intervertebral disc (IVD) disorders, including disc degeneration, disc herniation and lumbar or cervical radiculopathy[1-4]. TNFa is spontaneously produced by IVD tissues ex vivo[5,6], is expressed at higher levels in herniated IVD tissues from symptomatic patients compared to

CORRESPONDING AUTHOR: Please send correspondence to Lori A. Setton: 136 Hudson Hall Box 90821, Duke University, Durham, NC 27708 USA. setton@duke.edu Fax: 919-681-8490 Phone: 919-660-5141. 
asymptomatic or autoptic controls, and its expression levels increase with increasing radiographic grade of degeneration in the IVD $[1,7,8]$. Macrophages are key producers of $\mathrm{TNFa}$ and their increased presence in herniated and degenerated IVD tissues has been suggested as one of several sources in the IVD[9-12].

Cells of the IVD respond to proinflammatory stimuli (TNFa, lipopolysaccharide (LPS), and interleukin-1 beta (IL-1 $\beta$ )) in vitro with a net catabolic response characterized by decreased collagen and aggrecan synthesis, increased gene or protein expression for degradative collagenases, gelatinases and aggrecanases, as well as increased release of inflammatory mediators, such as nitric oxide (NO), prostaglandin $\mathrm{E}_{2}\left(\mathrm{PGE}_{2}\right)$, and interleukin-6 (IL6) [2,5,11,13-16]. TNFa exposure can also promote nerve growth factor (NGF) and NGF receptor expression in primary IVD cells in vitro[17]. Exogenous TNFa placed on dorsal root ganglia can induce decreased nerve conduction velocities[6,18] and increased mechanical allodynia and thermal hyperalgesia characteristic of IVD herniation in rat models $[18,19]$, which suggests a potential role for TNFa in regulating pain-related IVD pathology. Together, these studies have motivated interest in developing and characterizing therapies able to antagonize the inflammatory and catabolic events associated with TNFa exposure in the IVD[20-24].

While TNFa binds multiple receptors, two cell surface receptors, TNF receptors (TNFR) type I and II, are the most abundant and potent receptors for stimulating multiple apoptotic and pro-inflammatory pathways[25,26]. The molecular basis of TNFa signaling is complex and depends on cell lineage, but is known to involve the activation of NF- $\kappa \mathrm{B}, \mathrm{AP}-1$, and MAPK transduction factors in IVD cells[15,16]. Both p38 MAPK[14] and NF- $\kappa B$ inhibitors[27] have been studied as therapeutic targets for antagonizing intracellular effects of TNF in IVD cells, and two anti-proliferative antibiotics, minocycline $[28,29]$ and pentoxifylline[6], have been evaluated for treating neuropathic pain models in rats. TNFneutralizing antibodies have also been examined for mediating inflammation in IVD tissues in vitro[30], evaluated in animal models[3,6,31,32], and clinically for IVD herniationassociated radiculopathy[21].

Soluble cleavage products of the Type I and Type II TNF receptors (sTNFRI and sTNFRII respectively) retain a high affinity for $\mathrm{TNFa}[33]$ and function as decoy binding sites for this cytokine[34,35]. TNFa activity can hence be antagonized by sequestering soluble TNFa away from target receptors or by interacting with membrane-associated TNFa that will promote cytokine internalization and degradation. Clinical interest in the use of soluble receptors as TNF antagonists has led to the development of sTNFRI and sTNFRII analogues formed by conjugation or fusion to a macromolecular carrier, such as polyethylene glycol (PEG) or immunoglobulin G (IgG) constant domain (pegsunercept[36]; lenercept[37] and etanercept[38]). Clinical trials of systemic administration of etanercept, a sTNFRII:IgG fusion protein[38], have been conducted with the hope of reducing symptoms associated with lumbar radiculopathy[22,23]. While these and prior studies have shown interest in use of soluble TNF receptors or TNF-blocking antibodies for mediating nerve root-associated radiculopathy, data on the direct biological effects of sTNFR on IVD cells challenged with $\mathrm{TNFa}$ is not available. The objective of this study was to characterize the inflammatory response of human primary IVD cells following TNFa stimulation and test for a dosedependent attenuation of these effects with sTNFRII.

\section{METHODS}

\section{Isolation of human IVD cells}

Pathologic intervertebral disc tissues were obtained according to IRB approved protocols from 15 different patients undergoing surgery for treatment of degeneration or adult 
scoliosis $(\mathrm{n}=15)$. Tissues were procured from levels between L1 and L5 in patients ranging from 14 to 74 years of age. Regions corresponding to anulus fibrosus and nucleus pulposus were mechanically separated where possible, and only anulus fibrosus cells were isolated via enzymatic digestion as described previously[39] ( $0.3 \%$ pronase (Boehringer-Mannheim, Gaithersburg, MD, USA) and $0.3 \%$ collagenase II (Worthington Biochemical Corp., Lakewood, NJ, USA) per gram tissue). All reagents were obtained from Gibco (Invitrogen), unless otherwise noted. Cells were plated onto $25 \mathrm{~cm}^{2}$ tissue culture plastic flasks, overlaid with culture medium (F-12 medium with 10\% FBS (HyClone, Thermo Scientific, Waltham, MA, USA), $100 \mathrm{U} / \mathrm{ml}$ penicillin and $100 \mu \mathrm{g} / \mathrm{ml}$ streptomycin, $10 \mathrm{mM}$ HEPES, $1 \mu \mathrm{g} / \mathrm{ml}$ Fungizone) and allowed to grow to confluence with a change of culture medium every 2-3 days. Cells for all experiments were used within 2 passages of culture after isolation.

\section{Cell stimulation with TNFa and sTNFRII}

Cells were seeded in gelatin-coated wells of 48 -well plates (50,000 cells/well; 3 replicates per treatment group per patient sample), overlaid with $300 \mu l$ of culture medium, and allowed to attach for $24 \mathrm{hrs}$. Fresh culture medium $(300 \mu \mathrm{l})$ supplemented with $1.4 \mathrm{nM}$ rhTNFa (Abcam, Cambridge, MA, USA; $25 \mathrm{ng} / \mathrm{ml} ; 17.4 \mathrm{kDa}$ ) was added to attached cells; control cells received an exchange of culture medium without TNFa. Cells in one of four treatment groups were co-treated with rh-sTNFRII (Abcam; 18.9kDa) at 12.5, 25, 50, or 100 $\mathrm{nM}$, which was added at the same time as TNFa. All cells were cultured at $37^{\circ} \mathrm{C}$ and $5 \%$ $\mathrm{CO}_{2}$ for an additional $72 \mathrm{hrs}$ and supernatants were collected at the termination of all experiments and stored at $-20^{\circ} \mathrm{C}$ until quantitation.

\section{Quantitation of inflammatory mediators}

All supernatants for each patient were assayed for release of $\mathrm{NO}$ (Griess reaction)[40], $\mathrm{PGE}_{2}$ (ELISA, R\&D Systems, Minneapolis, MN, USA), and IL6 (ELISA, R\&D Systems). Standard curves for ELISAs were generated as prescribed by the manufacturer, and absorbance values of standards for $\mathrm{NO}$ quantitation were adjusted for the absence of culture medium.

Values for each inflammatory mediator in culture medium only were quantified and averaged across 3 replicates for each assay; this mean value was subtracted from corresponding data for each assay. A fold change from control (i.e., cells receiving no $\mathrm{TNFa}$ ) was also calculated for each sample receiving $\mathrm{TNFa}$ to determine relative increases in inflammatory mediator secretion. Values of each inflammatory mediator for cells receiving sTNFRII were normalized by corresponding values for cells receiving TNFa only as a measure of TNFa attenuation. Mean fold changes and attenuation fractions for each patient were calculated by averaging the range of values obtained from three control and three experimental replicates.

\section{Statistical analyses}

Box plots of NO, $\mathrm{PGE}_{2}$, and IL6 data for all patients were generated to calculate a median, upper quartile $\left(\mathrm{Q}_{3}\right)$, lower quartile $\left(\mathrm{Q}_{1}\right)$, and interquartile range $(\mathrm{IQR})$ for each data set. Medium-corrected data outliers-values greater or less than 1.5 IQR deviations from Q3 or Q1, respectively-were removed before calculating mean absolute responses to TNFa for all patients and fold-changes from control. A one-way ANOVA was used to detect differences in fold changes of $\mathrm{NO}, \mathrm{PGE}_{2}$, and IL6 levels between control and TNFa-treated cells at a significance level of 0.05. A one-way ANOVA with a post-hoc Tukey's HSD test was used to detect differences in attenuation of $\mathrm{NO}, \mathrm{PGE}_{2}$, and IL6 amongst groups receiving sTNFRII. Dose-dependent attenuation of TNFa-induced effects was further quantified by calculating an $\mathrm{IC}_{50}$ value for each inflammatory mediator. The attenuation fractions of $\mathrm{NO}, \mathrm{PGE}_{2}$, and IL6 for each patient for each dose of sTNFRII normalized to 
$\mathrm{TNFa}$ only treatment groups were fit by nonlinear regression to a logistic curve to derive half maximal inhibitory concentrations $\left(\mathrm{IC}_{50}\right)$ :

$$
X=X_{\min }+\frac{X_{\max }-X_{\min }}{1+\frac{[s T N F R I I]^{k}}{b}}
$$

where $X$ is the attenuation fraction of inflammatory mediator present relative to TNFa only controls, $X_{\min }$ is the minimal observed fraction, and $X_{\max }$ is the maximal observed fraction upon stimulation with TNFa. The Hill slope, $\mathrm{k}$, and $\mathrm{b}$ are fit parameters. Mean values for the normalized concentration of each inflammatory mediator for each patient were used to determine patient-specific $\mathrm{IC}_{50}$, and average values across all patients were reported. Outlier values for each mediator were not used in determination of $\mathrm{IC}_{50}$. Goodness of fit was reported as the coefficient of determination, $\mathrm{R}^{2}$; and upper and lower bounds of the $95 \%$ confidence interval were graphically generated.

\section{RESULTS}

\section{Human IVD cell response to TNFa}

Across all patients, $\mathrm{TNFa}(1.4 \mathrm{nM} ; 25 \mathrm{ng} / \mathrm{ml})$ induced a very large and statistically significant increase in release of $\mathrm{NO}, \mathrm{PGE}_{2}$, and IL6 (Table 1) from human primary IVD cells in vitro compared to controls cultured without TNFa, as expected. Control inflammatory mediator levels varied substantially amongst patient samples with individual sample responses to $\mathrm{TNFa}$ that ranged over 3 to 4 orders of magnitude for $\mathrm{NO}, \mathrm{PGE}_{2}$, and IL6 (Figure 1 and Table 1). Patient-matched fold-change responses to TNFa were calculated to account for inter-patient variability (Table 1) and mean fold-changes across all patients were reported.

\section{Attenuation of TNFa-induced inflammatory events}

Coincubation with sTNFRII significantly abated TNFa-induced release of $\mathrm{NO}$ and $\mathrm{PGE}_{2}$ from human IVD cells in a dose-dependent manner (Figure 2). In contrast, TNFa-induced release of IL6 was not attenuated by sTNFRII. Antagonist treatment groups were normalized to patient-matched TNFa only levels to account for variable absolute responses between patients. A directly proportional relationship between dose of sTNFRII and fractional attenuation of inflammatory mediator release was evident for $\mathrm{NO}$ and $\mathrm{PGE}_{2}$, with maximal attenuation fractions of 0.61 and 0.70 , respectively, at the highest sTNFRII dose tested (100 $\mathrm{nM})$.

Using two-parameter logistic non-linear regression models, $\mathrm{IC}_{50}$ values for secreted $\mathrm{NO}$ and $\mathrm{PGE}_{2}$ were calculated for each patient (see Equation 1). Goodness-of-fit was generally excellent $\left(\mathrm{R}^{2}>0.95\right)$. The mean $\mathrm{IC}_{50}$ doses of sTNFRII for NO and $\mathrm{PGE}_{2}$ release were found to be $35.1 \pm 9.0 \mathrm{nM}$ and $20.5 \pm 9.0 \mathrm{nM}$, respectively (mean $\pm \mathrm{SEM}$ ). Representative data fits for patients with $\mathrm{IC}_{50}$ values near median values for $\mathrm{NO}$ and $\mathrm{PGE}_{2}$ are shown in Figure 3. These results indicate that relatively low molar excesses of sTNFRII substantially attenuated the proinflammatory effects of TNFa on human IVD cells in vitro.

Attenuation of IL6 release followed an unexpected behavior for some patients. To investigate these results, sTNFRII $(50 \mathrm{nM})$ without TNFa was also added to cells from 5 individual patients and cultured for the same period of time under the same conditions. Surprisingly, the presence of sTNFRII alone at a concentration of 50nM induced a significant release of IL6 (1.41 \pm 0.04 fold-change; mean \pm SEM $)$ from human IVD cells $(\mathrm{n}=5)$, but did not affect $\mathrm{NO}$ or $\mathrm{PGE}_{2}$ release. This finding could explain the inability of sTNFRII to significantly moderate TNFa-induced release of IL6. 


\section{DISCUSSION}

The primary objective of this study was to investigate an ability for sTNFRII to antagonize $\mathrm{TNFa}$ induced inflammatory events in primary human IVD cells in vitro. Across all patients, TNFa induced large, statistically significant increases in NO, $\mathrm{PGE}_{2}$, and IL6 secretion from IVD cells compared to controls. For the sample population tested, there was no apparent effect of patient age on release of $\mathrm{NO}, \mathrm{PGE}_{2}$, or IL6. Coincubation of TNFa with nanomolar doses of sTNFRII significantly attenuated the secretion of $\mathrm{NO}$ and $\mathrm{PGE}_{2}$ in a dose-dependent manner. TNFa-induced secretion of IL6, however, was unchanged by the same concentrations of sTNFRII, a result that may be explained by a statistically significant induction of IL6 by sTNFRII without TNFa for a subset of patients. Attenuation data was fit to nonlinear regression models to calculate $\mathrm{IC}_{50}$ values for $\mathrm{NO}$ and $\mathrm{PGE}_{2}$ release for each patient. Mean $\mathrm{IC}_{50}$ values for $\mathrm{NO}$ and $\mathrm{PGE}_{2}$ were found to be $35.1 \pm 9.0 \mathrm{nM}$ and $20.5 \pm 9.0$ $\mathrm{nM}$, respectively (mean $\pm \mathrm{SEM}$ ), indicating that nanomolar concentrations of sTNFRII were able to significantly attenuate the effects of TNFa on primary human IVD cells in vitro.

Pathologic IVD tissue is known to exhibit an inflammatory phenotype characterized by infiltrating innate and adaptive immune cells, along with their pro-inflammatory chemokine products. Herniated and degenerate IVD tissue contain significantly higher levels of $\mathrm{TNFa}[1,7]$, and TNFa is known to be a key mediator of pain and inflammation associated with radiculopathy following herniation $[3,6,18,31,32]$. Our observed trends of increased secretion of key inflammatory mediators, $\mathrm{NO}, \mathrm{PGE}_{2}$, and IL6, from pathologic primary human IVD cells after exposure to TNFa corroborate previous reports of human nucleus pulposus (NP) cells cultured in alginate[14]. Studer et al.[14] challenged human NP cells in vitro with $\mathrm{TNFa}$, at a lower dose of $5 \mathrm{ng} / \mathrm{ml}$, and also saw significant increases in NO, $\mathrm{PGE}_{2}$, and IL6 secretion after 72 hours in culture. While induced secretion trends are similar to those reported here, differences in cell type, culture method, and dose of TNFa likely contribute to differences in absolute cell responses. The higher dose of TNFa, which was within the range of previous studies on IVD cell response to TNFa[2,14], was chosen to elicit a large enough inflammatory response such that attenuation with sTNFRII could be easily detected over a range of drug doses.

Quantitation of attenuation with sTNFRII revealed that low concentrations of sTNFRII were able to significantly attenuate TNFa effects, which further supports claims that targeting $\mathrm{TNFa}$ in IVD pathologies can reduce inflammation. The observed $\mathrm{IC}_{50}$ values for attenuating $\mathrm{NO}$ and $\mathrm{PGE}_{2}$ secretion with sTNFRII were roughly 20- to 30 -fold higher than the supplemented concentration of $\mathrm{TNFa}$, consistent with the $\mathrm{IC}_{50}$ range reported for inhibition of cell death for the $\mathrm{L} 929$ murine fibrosarcoma cell line $\left(\mathrm{IC}_{50}=6.6 \mathrm{nM}\right.$ sTNFRII, $\mathrm{TNFa}=14 \mathrm{pM}$, or 470-fold molar excess) (Abcam)[41]. While anti-TNF antibodies have lower reported $\mathrm{IC}_{50}$ values than sTNFRI and sTNFRII in the same assay (Abcam), the smaller size of the soluble receptor-based drugs lends toward more facile synthesis, coupling to drug carrier vehicles, and more rapid clearance to minimize morbidity associated with delivery of these immunosuppresives. Indeed, incorporation of TNF antagonists into engineered, sustained release drug formulations may be a crucial aspect of the design of novel IVD therapeutics, in order to minimize the undesirable side effects of delivering potent TNF antagonists and other immunosuppresives systemically. Soluble TNF receptorbased therapies provide the benefits of high affinity and low molecular weight for designing locally delivered, sustained release systems for treating IVD pathologies[42,43].

TNFa is likely not the only mediator of pathology in the IVD, with some data indicating a more crucial role for IL- $1 \beta$ in initiating matrix catabolism and IVD degeneration[30]. However, the robust inflammatory response of pathologic IVD cells to TNFa reported herein supports previous findings $[2,7,11,13,15,16]$ and motivates continued interest in 
targeting TNFa for treating IVD pathologies. In this study, nanomolar concentrations of sTNFRII conferred a potent antagonistic effect on TNFa-induced secretion of $\mathrm{NO}$ and $\mathrm{PGE}_{2}$ in vitro, but did not attenuate IL6 release. Interestingly, intracellular antagonism of TNFa with a p38 MAPK inhibitor[14] had a statistically significant effect on PGE $_{2}$ and IL6, but had no effect on NO, whereas we observed effects on $\mathrm{NO}_{\text {and }} \mathrm{PGE}_{2}$, but not IL6 secretion, using an extracellular-acting antagonist. Blocking the TNFa signaling cascade before TNFR activation, as done here, would suggest that differences in intracellular signaling cascade upregulation for these mediators only partly contribute to differences in our findings for IL6. Rather, sTNFRII may be interacting with another membrane-bound component of pathologic IVD cells, such as membrane bound TNFa, and lead to the activation of cascades specific to IL6, but not $\mathrm{NO}$ or $\mathrm{PGE}_{2}$ upregulation. Future studies utilizing separate intracellular signaling pathway inhibitors may elucidate differences in regulatory mechanisms between NO, $\mathrm{PGE}_{2}$, and IL6, as well as the unexpected effect of sTNFRII on IL6. The effect of TNFa on extracellular matrix synthesis or protease expression for IVD cells was not measured in this study, but may be of tremendous interest in future studies as the effects of TNFa and sTNFRII on net catabolic activity as well as net matrix synthesis may be expected to differ.

$\mathrm{NO}, \mathrm{PGE}_{2}$, and IL6 are known to have pro- and anti-inflammatory activities in osteoarthritis models and articular chondrocytes[44], but these cytokines' exact roles in IVD pathologies require further definition. Herniated IVD specimens have been shown to produce $\mathrm{NO}, \mathrm{PGE}_{2}$, and IL6[5,45], as well as a host of other inflammatory mediators [11,13], spontaneously in vitro or after stimulation with proinflammatory cytokines. Nitric oxide has been shown to mediate the change in proteoglycan synthesis in human IVD explants in response to hydrostatic pressure[46], as well as pain-related behavior in a rat model of radiculopathy[47]. $\mathrm{PGE}_{2}$ is a product of cyclooxygenase-2 (COX-2) activity, an enzyme implicated in the pathology of IVD herniation[48,49], and epidural injection of a COX-2 inhibitor for treating a rat radiculopathy model significantly alleviated mechanical allodynia[50]. IL6 may play a role in activating or attracting glial cells to sites of nerve injury[51], or may be a key inflammatory product of glial cells recruited to some nerve root injuries[52]. Some association between IL6 protein levels and painful manifestations of disc degeneration, but not normal disc physiology, has been demonstrated[11]. Interestingly, in one rat radiculopathy model, IL6 protein levels were observed to increase following local delivery of a pharmacologic cocktail of IL-1 receptor antagonist and sTNFRI[51]. This finding mirrors our own observations of increased IL6 induction by sTNFRII without TNFa by primary IVD cells and may imply a similar mechanism persists for other relevant cell types of this pathology. While the roles of $\mathrm{NO}, \mathrm{PGE}_{2}$, and IL6 are not entirely clear, they each represent good measures of inflammation in response to TNFa. The substantially greater release of $\mathrm{NO}$ and $\mathrm{PGE}_{2}$ from our studies (Figure 1) suggests these two inflammatory mediators may be better readouts for evaluating new TNF antagonists in vitro.

\section{CONCLUSION}

Human primary IVD cells responded to TNFa in vitro by releasing large, statistically significant levels of NO, PGE2, and IL6 compared to controls. We report in vitro evidence of the effects of sTNFRII on pathologic IVD cells stimulated with TNFa, wherein nanomolar doses of sTNFRII were able to significantly attenuate TNFa-induced secretion of key inflammatory mediators. These findings highlight the importance of targeting TNFa in inflammatory pathologies of the IVD and emphasize the value of using soluble TNF receptors, and their analogues, to treat such pathologies. Any future TNF antagonists and related drug delivery formulations for treating IVD pathologies may benefit from the $\mathrm{IC}_{50}$ data reported herein as a metric for evaluating new drug performance and bioactivity before proceeding to pre-clinical animal models. 


\section{Acknowledgments}

This work was funded by the NIH (R01AR047442, P01AR050245, R01AR057410) and the Duke BME Howard Clark Pre-Doctoral Fellowship.

\section{References}

1. Le Maitre C, Hoyland J, Freemont A. Catabolic cytokine expression in degenerate and herniated human intervertebral discs: IL-1 and TNF expression profile. Arthritis Research \& Therapy. 2007; 9:R77. [PubMed: 17688691]

2. Séguin CA, Pilliar RM, Roughley PJ, Kandel RA. Tumor necrosis factor [alpha] modulates matrix production and catabolism in nucleus pulposus tissue. Spine. 2005; 30:1940. [PubMed: 16135983]

3. Olmarker K, Rydevik B. Selective inhibition of tumor necrosis factor-[alpha] prevents nucleus pulposus-induced thrombus formation, intraneural edema, and reduction of nerve conduction velocity: possible implications for future pharmacologic treatment strategies of sciatica. Spine. 2001; 26:863. [PubMed: 11317106]

4. Peng B, Hao J, Hou S, Wu W, Jiang D, Fu X, Yang Y. Possible pathogenesis of painful intervertebral disc degeneration. Spine. 2006; 31:560. [PubMed: 16508552]

5. Kang JD, Georgescu HI, McIntyre-Larkin L, Stefanovic-Racic M, Donaldson WF III, Evans CH. Herniated lumbar intervertebral discs spontaneously produce matrix metalloproteinases, nitric oxide, interleukin-6, and prostaglandin E2. Spine. 1996; 21:271. [PubMed: 8742201]

6. Olmarker K, Larsson K. Tumor Necrosis Factor [alpha] and Nucleus-Pulposus-Induced Nerve Root Injury. Spine. 1998; 23:2538. [PubMed: 9854752]

7. Weiler C, Nerlich AG, Bachmeier BE, Boos N. Expression and distribution of tumor necrosis factor alpha in human lumbar intervertebral discs: a study in surgical specimen and autopsy controls. Spine. 2005; 30:44. [PubMed: 15626980]

8. Nygaard Ø, Mellgren SI, Østerud B. The inflammatory properties of contained and noncontained lumbar disc herniation. Spine. 1997; 22:2484. [PubMed: 9383853]

9. Haro H, Shinomiya K, Komori H, Okawa A, Saito I, Miyasaka N, Furuya K. Upregulated expression of chemokines in herniated nucleus pulposus resorption. Spine. 1996; 21:1647. [PubMed: 8839466]

10. Matsui Y, Maeda M, Nakagami W, Iwata H. The involvement of matrix metalloproteinases and inflammation in lumbar disc herniation. Spine. 1998; 23:863. [PubMed: 9580952]

11. Burke JG, Watson RWG, McCormack D, Dowling FE, Walsh MG, Fitzpatrick JM. Intervertebral discs which cause low back pain secrete high levels of proinflammatory mediators. Journal of Bone \& Joint Surgery, British Volume. 2002; 84:196-201.

12. Demircan MN, Asir A, Cetinkal A, Gedik N, Kutlay AM, Colak A, Kurtar S, Simsek H. Is there any relationship between proinflammatory mediator levels in disc material and myelopathy with cervical disc herniation and spondylosis? A non-randomized, prospective clinical study. European Spine Journal. 2007; 16:983-986. [PubMed: 17476536]

13. Burke JG, Watson RWG, Conhyea D, McCormack D, Dowling FE, Walsh MG, Fitzpatrick JM. Human nucleus pulposis can respond to a pro-inflammatory stimulus. Spine. 2003; 28:2685. [PubMed: 14673370]

14. Studer RK, Aboka AM, Gilbertson LG, Georgescu H, Sowa G, Vo N, Kang JD. p38 MAPK inhibition in nucleus pulposus cells: a potential target for treating intervertebral disc degeneration. Spine. 2007; 32:2827. [PubMed: 18246004]

15. Séguin CA, Bojarski M, Pilliar RM, Roughley PJ, Kandel RA. Differential regulation of matrix degrading enzymes in a TNF -induced model of nucleus pulposus tissue degeneration. Matrix Biology. 2006; 25:409-418. [PubMed: 16934445]

16. Séguin CA, Pilliar RM, Madri JA, Kandel RA. TNF-[alpha] Induces MMP2 Gelatinase Activity and MT1-MMP Expression in an In Vitro Model of Nucleus Pulposus Tissue Degeneration. Spine. 2008; 33:356. [PubMed: 18277865] 
17. Abe Y, Akeda K, An HS, Aoki Y, Pichika R, Muehleman C, Kimura T, Masuda K. Proinflammatory cytokines stimulate the expression of nerve growth factor by human intervertebral disc cells. Spine. 2007; 32:635. [PubMed: 17413467]

18. Aoki Y, Rydevik B, Kikuchi S, Olmarker K. Local application of disc-related cytokines on spinal nerve roots. Spine. 2002; 27:1614. [PubMed: 12163720]

19. Igarashi T, Kikuchi S, Shubayev V, Myers RR. Exogenous tumor necrosis factor-alpha mimics nucleus pulposus-induced neuropathology: molecular, histologic, and behavioral comparisons in rats. Spine. 2000; 25:2975. [PubMed: 11145807]

20. Goupille P, Mulleman D, Chevalier X. Is interleukin-1 a good target for therapeutic intervention in intervertebral disc degeneration: lessons from the osteoarthritic experience. Arthritis Research \& Therapy. 2007; 9:110. [PubMed: 18086327]

21. Korhonen T, Karppinen J, Paimela L, Malmivaara A, Lindgren KA, Bowman C, Hammond A, Kirkham B, Järvinen S, Niinimäki J. The treatment of disc herniation-induced sciatica with infliximab: one-year follow-up results of FIRST II, a randomized controlled trial. Spine. 2006; 31:2759. [PubMed: 17108825]

22. Genevay S, Stingelin S, Gabay C. Efficacy of etanercept in the treatment of acute, severe sciatica: a pilot study. Annals of the Rheumatic Diseases. 2004; 63:1120-1123. [PubMed: 15115710]

23. Cohen SP, Bogduk N, Dragovich A, Buckenmaier CC III, Griffith S, Kurihara C, Raymond JL, Richter PJ, Williams N, Yaksh TL. Randomized, double-blind, placebo-controlled, dose-response, and preclinical safety study of transforaminal epidural etanercept for the treatment of sciatica. Anesthesiology. 2009; 110:1116. [PubMed: 19387178]

24. Tobinick E, Davoodifar S. Efficacy of etanercept delivered by perispinal administration for chronic back and/or neck disc-related pain: a study of clinical observations in 143 patients. Current Medical Research and Opinion ${ }^{\circledR}$. 2004; 20:1075-1085. [PubMed: 15265252]

25. Chen G, Goeddel DV. TNF-R1 signaling: a beautiful pathway. 2002; 296:1634-1635.

26. Liu Z, Han J. Cellular responses to tumor necrosis factor. Current Issues in Molecular Biology. 2001; 3:79-90. [PubMed: 11719971]

27. Akeda K, An HS, Gemba T, Okuma M, Miyamoto K, Chujyo T, Kitahara S, Masuda K. P89 The intra-discal injection of naked NF [kappa] B decoy oligonucleotide is effective in restoring disc degeneration in the rabbit annular needle puncture model. The Spine Journal. 2005; 5:S152-S153.

28. Raghavendra V, Tanga F, DeLeo JA. Inhibition of microglial activation attenuates the development but not existing hypersensitivity in a rat model of neuropathy. Journal of Pharmacology and Experimental Therapeutics. 2003; 306:624. [PubMed: 12734393]

29. Ledeboer A, Sloane EM, Milligan ED, Frank MG, Mahony JH, Maier SF, Watkins LR. Minocycline attenuates mechanical allodynia and proinflammatory cytokine expression in rat models of pain facilitation. Pain. 2005; 115:71-83. [PubMed: 15836971]

30. Hoyland JA, Le Maitre C, Freemont AJ. Investigation of the role of IL-1 and TNF in matrix degradation in the intervertebral disc. Rheumatology. 2008; 47:809. [PubMed: 18397957]

31. Olmarker K, Nutu M, Størkson R. Changes in spontaneous behavior in rats exposed to experimental disc herniation are blocked by selective TNF-alpha inhibition. Spine. 2003; 28:16351642. [PubMed: 12897484]

32. Onda A, Yabuki S, Kikuchi S. Effects of neutralizing antibodies to tumor necrosis factor-alpha on nucleus pulposus-induced abnormal nociresponses in rat dorsal horn neurons. Spine. 2003; 28:967. [PubMed: 12768133]

33. Chen PCH, DuBois GC, Chen MJ. Mapping the domain (s) critical for the binding of human tumor necrosis factor-alpha to its two receptors. Journal of Biological Chemistry. 1995; 270:2874. [PubMed: 7852363]

34. Engelmann H, Novick D, Wallach D. Two tumor necrosis factor-binding proteins purified from human urine. Evidence for immunological cross-reactivity with cell surface tumor necrosis factor receptors. Journal of Biological Chemistry. 1990; 265:1531-1536. [PubMed: 2153136]

35. Hale KK, Smith CG, Baker SL, Vanderslice RW, Squires CH, Gleason TM, Tucker KK, Kohno T, Russell DA. Multifunctional regulation of the biological effects of TNF-by the soluble type I and type II TNF receptors. Cytokine. 1995; 7:26-38. [PubMed: 7749064] 
36. Edwards CK. PEGylated recombinant human soluble tumour necrosis factor receptor type I (r-HusTNF-RI): novel high affinity TNF receptor designed for chronic inflammatory diseases. British Medical Journal. 1999; 58:73-81.

37. Abraham E, Laterre PF, Garbino J, Pingleton S, Butler T, Dugernier T, Margolis B, Kudsk K, Zimmerli W, Anderson P. Lenercept (p55 tumor necrosis factor receptor fusion protein) in severe sepsis and early septic shock: A randomized, double-blind, placebo-controlled, multicenter phase III trial with 1,342 patients. CRITICAL CARE MEDICINE-BALTIMORE-. 2001; 29:503-510.

38. Peppel K, Crawford D, Beutler B. A tumor necrosis factor (TNF) receptor-IgG heavy chain chimeric protein as a bivalent antagonist of TNF activity. Journal of Experimental Medicine. 1991; 174:1483-1489. [PubMed: 1660525]

39. Baer AE, Wang JY, Kraus VB, Setton LA. Collagen gene expression and mechanical properties of intervertebral disc cell-alginate cultures. Journal of Orthopaedic Research. 2001:19.

40. Miles AM, Wink DA, Cook JC, Grisham MB. Determination of nitric oxide using fluorescence spectroscopy. Methods in enzymology. 1996; 268:105-120. [PubMed: 8782577]

41. Tomkins PKC, Webber D, Bowen G. The L929 cell bioassay for murine tumour necrosis factor is not influenced by other murine cytokines. J Immunol Methods. 1992; 151:313-315. [PubMed: 1629621]

42. Shamji MF, Chen J, Friedman AH, Richardson WJ, Chilkoti A, Setton LA. Synthesis and characterization of a thermally-responsive tumor necrosis factor antagonist. Journal of Controlled Release. 2008; 129:179-186. [PubMed: 18547669]

43. Shamji MF, Whitlatch L, Friedman AH, Richardson WJ, Chilkoti A, Setton LA. An injectable and in situ-gelling biopolymer for sustained drug release following perineural administration. Spine. 2008; 33:748. [PubMed: 18379401]

44. Loeser RF. Molecular mechanisms of cartilage destruction: mechanics, inflammatory mediators, and aging collide. Arthritis and rheumatism. 2006; 54:1357. [PubMed: 16645963]

45. Kang JD, Stefanovic-Racic M, McIntyre LA, Georgescu HI, Evans CH. Toward a biochemical understanding of human intervertebral disc degeneration and herniation: contributions of nitric oxide, interleukins, prostaglandin E2, and matrix metalloproteinases. Spine. 1997; 22:1065. [PubMed: 9160463]

46. Liu GZ, Ishihara H, Osada R, Kimura T, Tsuji H. Nitric oxide mediates the change of proteoglycan synthesis in the human lumbar intervertebral disc in response to hydrostatic pressure. Spine. 2001; 26:134. [PubMed: 11154531]

47. Kawakami M, Tamaki T, Hashizume H, Weinstein JN, Meller ST. The role of phospholipase A2 and nitric oxide in pain-related behavior produced by an allograft of intervertebral disc material to the sciatic nerve of the rat. Spine. 1997; 22:1074. [PubMed: 9160464]

48. Miyamoto H, Saura R, Harada T, Doita M, Mizuno K. The role of cyclooxygenase-2 and inflammatory cytokines in pain induction of herniated lumbar intervertebral disc. Kobe Journal of Medical Sciences. 2000; 46:13-28. [PubMed: 11193500]

49. Miyamoto H, Saura R, Doita M, Kurosaka M, Mizuno K. The role of cyclooxygenase-2 in lumbar disc herniation. Spine. 2002; 27:2477. [PubMed: 12435978]

50. Kawakami M, Matsumoto T, Hashizume H, Kuribayashi K, Tamaki T. Epidural injection of cyclooxygenase-2 inhibitor attenuates pain-related behavior following application of nucleus pulposus to the nerve root in the rat. Journal of Orthopaedic Research. 2002; 20:376-381. [PubMed: 11918320]

51. Winkelstein BA, Rutkowski MD, Sweitzer SM, Pahl JL, DeLeo JA. Nerve injury proximal or distal to the DRG induces similar spinal glial activation and selective cytokine expression but differential behavioral responses to pharmacologic treatment. The Journal of Comparative Neurology. 2001; 439:127-139. [PubMed: 11596043]

52. Colburn RW, Rickman AJ, DeLeo JA. The effect of site and type of nerve injury on spinal glial activation and neuropathic pain behavior. Experimental Neurology. 1999; 157:289-304. [PubMed: 10364441] 


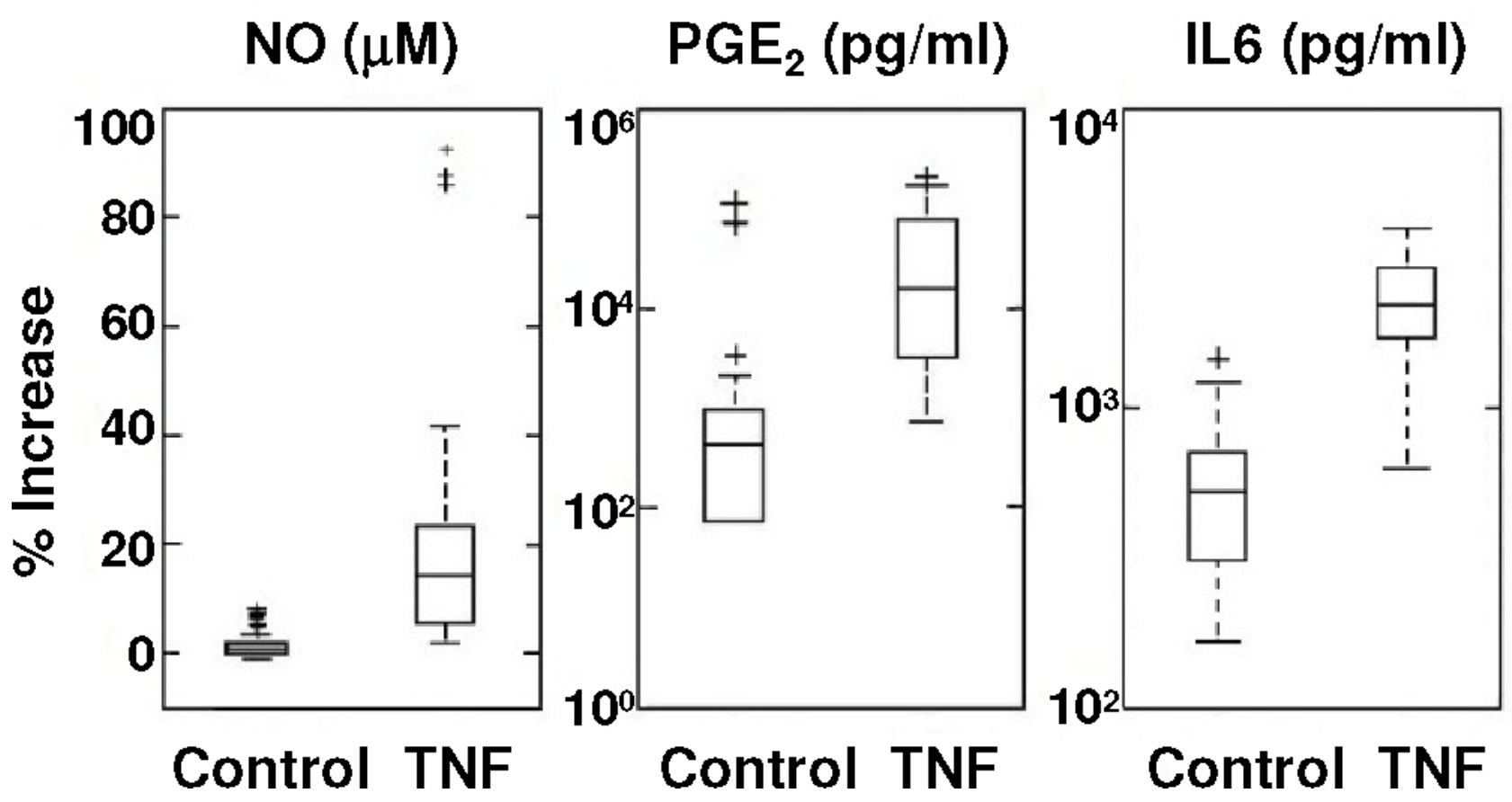

Figure 1.

Box plots of $\mathrm{NO}, \mathrm{PGE}_{2}$, and IL6 release for all patients, including outliers (+) (see methods). Patient responses to TNFa ranged over multiple log scales for all three mediators. See Table 1 for additional presentation. 


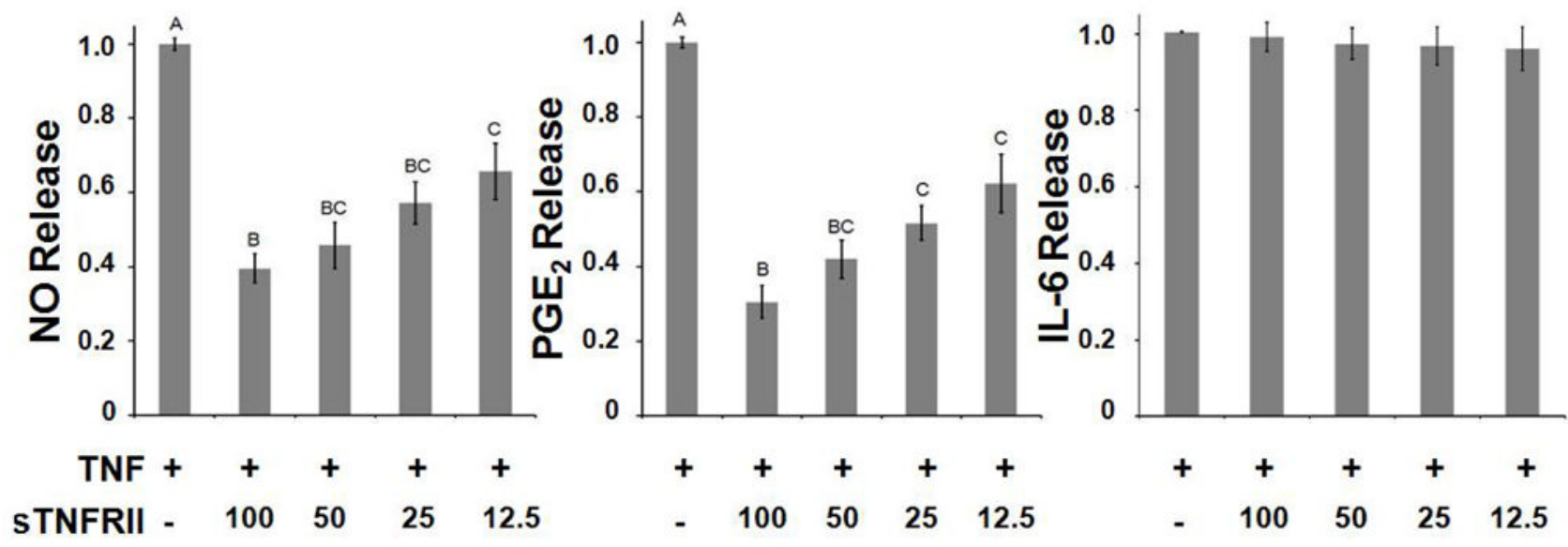

Figure 2.

Dose-dependent attenuation of TNFa-induced release of NO (left; $\mathrm{p}<10^{-10}$ ), $\mathrm{PGE}_{2}$ (middle; $\mathrm{p}<10^{-3}$ ), and IL6 (right) after $72 \mathrm{hr}$ incubation with $25 \mathrm{ng} / \mathrm{ml} \mathrm{TNFa}$ averaged across all patients $(n=15)$. Values are reported as mass fractions, normalized to TNFa only control values (mean \pm SEM) $(12.5-100 \mathrm{nM})$; groups without common letters are significantly different (one-way ANOVA with post-hoc Tukey's HSD). 


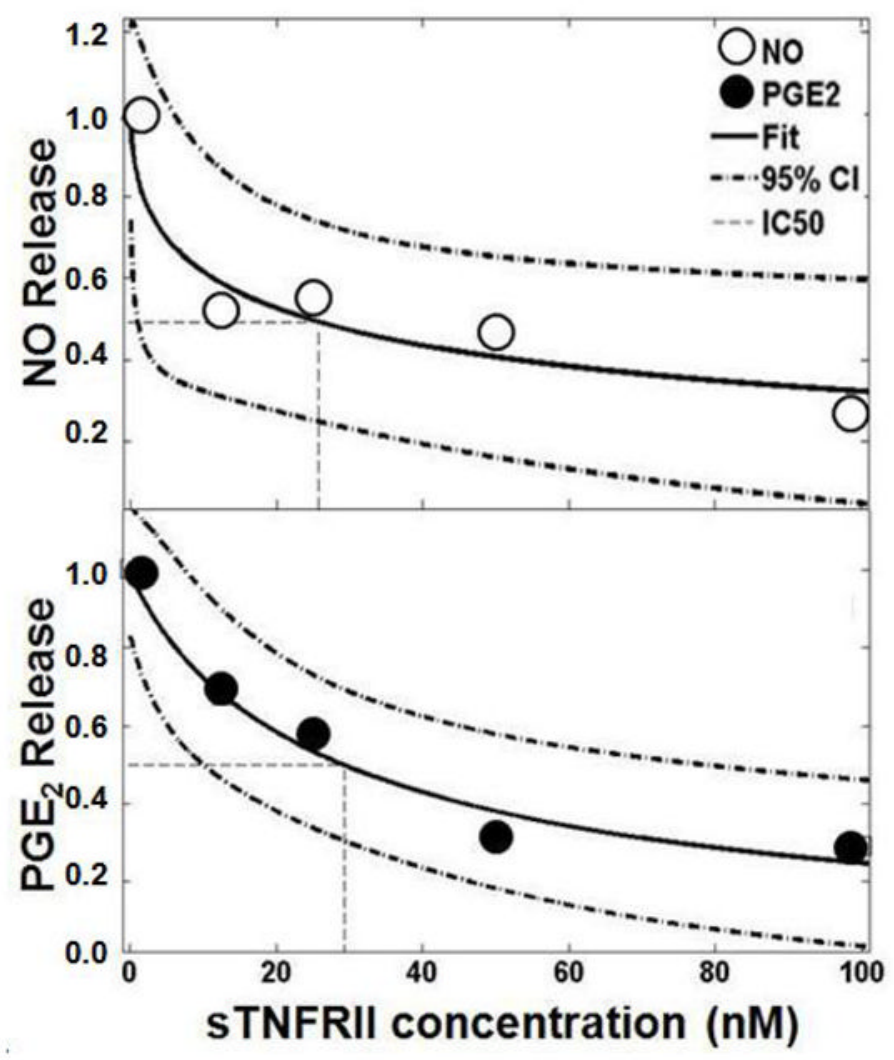

Figure 3.

Logistic regression modeling of dose-dependent attenuation of $\mathrm{NO}$ and $\mathrm{PGE}_{2}$ release plotted against dose of sTNFRII. A representative data set is shown. $\mathrm{IC}_{50}$ values were calculated for each patient from fit parameters $b$ and $k$, and a mean \pm SEM was calculated. NO figure parameters $\left(\mathrm{R}^{2}=0.95, \mathrm{IC}_{50}=24, \mathrm{~b}=5.3, \mathrm{k}=0.52\right)$. $\mathrm{PGE}$ figure parameters $\left(\mathrm{R}^{2}=0.97, \mathrm{IC}_{50}\right.$ $=29, \mathrm{~b}=21, \mathrm{k}=0.90)$. 


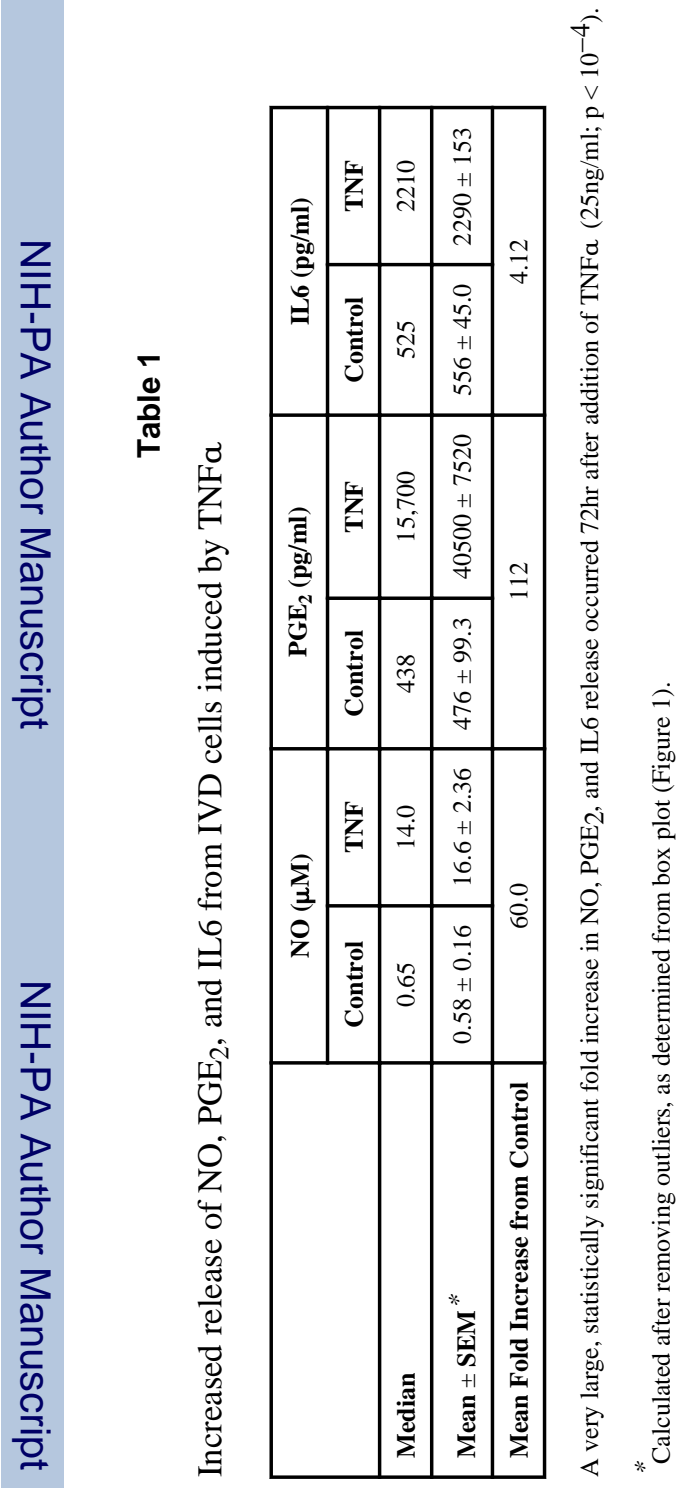

Spine (Phila Pa 1976). Author manuscript; available in PMC 2012 July 01. 